\title{
Construction and first deployment of the JOIDES Resolution's Secchi discs ${ }^{1}$
}

\author{
Bryce Hoppie, ${ }^{2}$ Timothy R. Bronk, ${ }^{3}$ and the Expedition 329 Scientists $^{2}$
}

\section{Chapter contents}

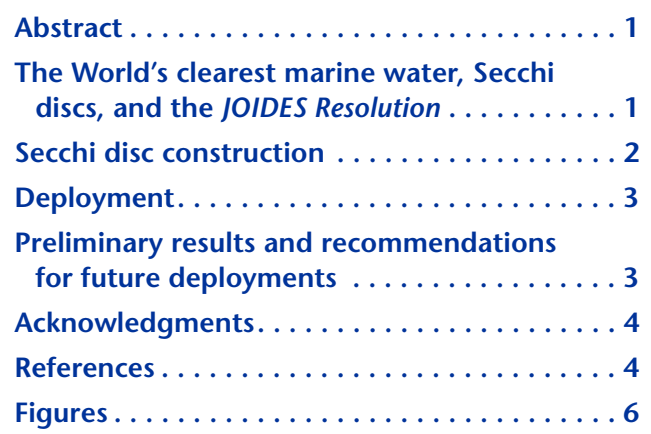

'Hoppie, B., Bronk, T.R., and the Expedition 329 Scientists, 2011. Construction and first deployment of the JOIDES Resolution's Secchi discs. In D'Hondt, S., Inagaki, F., Alvarez Zarikian, C.A., and the Expedition 329 Scientists, Proc. IODP, 329: Tokyo (Integrated Ocean Drilling Program Management International, Inc.). doi:10.2204/iodp.proc.329.111.2011

'Expedition 329 Scientists' addresses.

${ }^{3}$ Integrated Ocean Drilling Program, Texas A\&M University, College Station TX 77843-3146, USA.

\section{Abstract}

The Secchi disc is a tool for measuring water transparency. For over a century, the device has been used in pelagic environments to assess surface productivity and overall water purity. Two new Secchi discs were constructed and tested during Integrated Ocean Drilling Program Expedition 329 for use by staff of the R/V JOIDES Resolution during future expeditions. The results of the initial deployments of the discs during the expedition in the center of the South Pacific Gyre, the world's "clearest" marine water, are presented here.

\section{The world's clearest marine water, Secchi discs, and the JOIDES Resolution}

The center of the South Pacific Gyre purportedly holds the world's clearest marine water (Claustre et al., 2008). The elliptical center of the gyre between $20^{\circ}-30^{\circ} \mathrm{S}$ and $98^{\circ}-122^{\circ} \mathrm{W}$ is largely devoid of the suspended solids (i.e., particulate organic matter, plankton tests/frustules, and clay) that limit the transparency of surface marine water (Jerov, 1968; Gordon and McCluney, 1975). A variety of optical measurements performed by oceanographers during the past 20 y confirm the clarity of the gyre's center (see Claustre et al., 2008). For example, Claustre et al., (1999) and Morel et al. (2007) show that photosynthetic-available radiation, the range of light between 400 and $700 \mathrm{~nm}$ used by autotrophic organisms, penetrates to a minimum depth of 100-150 meters below sea level (mbsl). The extremely low abundances of organic matter and planktonic tests/frustules are also confirmed by in situ and remote-sensing ocean color sensors that report maximum seasonal total chlorophyll concentrations of $0.02 \mathrm{mg} / \mathrm{m}^{3}$ for NovemberJanuary and $0.045 \mathrm{mg} / \mathrm{m}^{3}$ for June-August (Fougnie et al., 2002; Morel and Maritorena, 2001).

The absence of suspended terrigenous solids in the water column is inferred from the exceedingly low accumulation rate of clay particles in seafloor sediment underlying the center of the gyre. Scientific drilling into the seafloor near the center of the gyre recovered $14 \mathrm{~m}$ of calcareous nannofossil ooze deposited on $4 \mathrm{Ma}$ basaltic crust (see the "Site U1368" chapter [Expedition 329 Scientists, 2011]). Microfossils showed limited dissolution effects, and thus it is likely that the recovered sediment accurately depicts total sediment flux to the seafloor. Clay content within the ooze 
is between $0 \%$ and $10 \%$. Thus, the maximum decompacted accumulation rate of clay on the seafloor, a proxy for the concentration of clay particles in the overlying water column, is $\sim 0.4 \mu \mathrm{m} / \mathrm{y}$. Given that the clay particles accumulating on the seafloor during any year during the past $4 \mathrm{~m} . \mathrm{y}$. are distributed through a column of water $>2500 \mathrm{~m}$ thick, it is fair to assume that the concentration of clay in any cubic meter of the water column is practically zero. It should be noted that other scientific coring results have been interpreted to indicate that the flux of clay to the seafloor in the center of the gyre could be zero (Rea et al., 2006).

The Secchi disc is a tool for measuring water transparency. For over a century, the device has been used in pelagic environments to assess surface productivity and overall water purity (Cialdi, 1866; Boguslawski and Krümmel, 1907; Clarke, 1939; Riley, 1957). The disc is continuously lowered into water, and the depth at which visual contact is lost is recorded. The disc is lowered to an unspecified additional depth and then raised until it becomes visually recognized. The depth at which it becomes recognized is also recorded. The average of the depth at which visual contact is lost during lowering and the depth at which it becomes visible during raising is called the Secchi disc transparency (SDT) (Tyler, 1968). Although the method is highly subjective, its widespread and long-term use makes it a staple of hydrologic investigations (Bukata et al., 1988). The results are very useful for tracking temporal changes in water transparency at designated locations that are revisited by a common set of observers (see www.ecy.wa.gov/programs/wq/plants/management/ joysmanual/4secchi.html). For example, historical records of Secchi disc measurements have been used to determine how phytoplankton in the North Atlantic have responded to increases in anthropogenic $\mathrm{CO}_{2}$ in the past century (Falkowski and Wilson, 1992). However, the subjectivity of the method and variability in factors that impact overall water transparency makes comparisons of SDTs from different water bodies untenable.

The R/V JOIDES Resolution is an ideal platform for deploying a Secchi disc. The ship regularly circumnavigates the world oceans and positions itself far from coastlines for periods from 2 to 60 days. As an integral component of its drilling mission, the position of the ship is known precisely and heave-related effects are intentionally minimized. Finally, the ship is equipped with hydraulic cranes and winches for raising and lowering a large-scale Secchi disc and a deployable small watercraft for positioning observers near the water surface. Therefore, the JOIDES Resolu- tion represents a near-ideal marine platform for traveling the world oceans and acquiring SDT data.

This paper provides details pertaining to the construction of two new Secchi discs intended for use by staff of the JOIDES Resolution during future expeditions. It also documents the results of the initial deployments of the discs during Expedition 329 in the center of the South Pacific Gyre, the world's "clearest" marine water.

\section{Secchi disc construction}

We constructed two Secchi discs similar to those used previously by investigators in the North Atlantic Ocean (Fig. F1). As reported by Visser (1967), the Royal Netherlands Navy's sweeping survey of the North Atlantic in 1964 and 1965 utilized one smalldiameter $(1 \mathrm{ft})$ and one large-diameter $(1 \mathrm{~m})$ disc. Our discs mimicked this 1:3 size ratio but used the currently more widely employed $40 \mathrm{~cm}$ diameter disc as our small-diameter instrument and a $1.2 \mathrm{~m}$ diameter disc as our larger instrument.

The smaller Secchi disc was custom built but essentially replicated the design parameters of discs that are commonly available through environmental monitoring equipment retailers. It was cut from $3 / 8$ inch high-density plastic and painted in the standard black and white quadrant pattern. The black quadrants were covered with matte black spray paint (Nippo) and the white quadrants with glossy white spray paint (Rustoleum). An eyebolt was installed in the center of the disc as the mounting point for weights and line. Two strands of high tensilestrength tarred marlin line were tied to the eyebolt and used for lowering and hoisting the disc. A $\sim 5 \mathrm{~kg}$ shackle was threaded through the eyebolt and provided the weight needed to draw the rope taught during deployment.

Our second Secchi disc was constructed with the purpose of improving our ability to recognize a small object at a great distance. That is, our $40 \mathrm{~cm}$ Secchi disc at an anticipated depth (distance) of over $60 \mathrm{~m}$ would represent an object no larger than $8.5 \mathrm{~mm}$ in diameter to one of our observers. Given this small target size and anticipated scattering caused by surface disturbances (and that the objective of the exercise is to assess water transparency and not the keenness of the observers' vision), we selected a diameter of $1.2 \mathrm{~m}$ for our second disc. This size is not without precedent: Boguslawski and Krümmel (1907) used a $2 \mathrm{~m}$ diameter Secchi disc for his observations of water transparency in the Sargasso Sea. Our disc also required additional rigging to maintain the horizontal 
surface needed to optimize visual identification of a distinct, reflective surface (Tyler, 1968). Our larger disc was cut from similar plastic and painted in the same manner as our smaller disc. Twenty-eight 5.08 $\mathrm{cm}$ diameter holes were cut through the black quadrants to facilitate vertical motion through the water and reduce pitch, roll, and yaw of the disc that could result from current flow across its broad surface. An additional measure incorporated into the disc design involved rigging the disc from two sets of antipodal points rather than one central point. The four-part harness was constructed of $1 / 4$ inch cables secured to eyebolts installed just inboard of the disc's perimeter. An eyebolt was installed in the center as an anchor for weights. A total of $11 \mathrm{~kg}$ of weight was attached to this anchor bolt. A $3 / 8$ inch polypropylene rope was fitted with a shackle and marked with permanent marker and cable ties in $10 \mathrm{~m}$ lengths. The interval between 60 and $70 \mathrm{~m}$ was marked in additional $1 \mathrm{~m}$ lengths. A total of $140 \mathrm{~m}$ of this line was installed on a hydraulic winch located next to the crane.

\section{Deployment}

\section{Small disc}

Date: 13 November 2010

Location: $27^{\circ} 55.0024^{\prime} \mathrm{S}, 123^{\circ} 9.6679^{\prime} \mathrm{W}$

The first deployment was done at noon in slightly choppy seas. The tarred marlin line was routed through a pulley installed on the end of a Venturo Cranes HT40KXP crane mounted at the starboard aft end of the JOIDES Resolution. The crane was extended to $6.1 \mathrm{~m}$ and held $\sim 7.6 \mathrm{~m}$ above the sea surface. Three observers were stationed alongside the ship railing (at the same level as the crane) with an additional person reeling out line as needed. The disc was lowered until it was no longer visible by any observer and then reeled back in. A knot was tied in the line where it was wet from immersion. The line was then laid out on the JOIDES Resolution helideck and measured (Fig. F2). We measured $46.5 \mathrm{~m}$ from the knot to the Secchi disc.

\section{First deployment}

\section{Large disc}

Date: 16 November 2010

Location: $27^{\circ} 54.9916^{\prime} \mathrm{S}, 123^{\circ} 9.6681^{\prime} \mathrm{W}$

The first deployment of the $1.2 \mathrm{~m}$ disc was a test run to check stability of the large disc and practice the task of hanging the cumbersome object over the side of the ship. With three observers and an operator for the winch, the Secchi disc was deployed to $48 \mathrm{mbsl}$ until the ocean surface conditions (wave chop and glare) made it difficult to make accurate observations. The disc was then retrieved and plans were made to try again when weather conditions were favorable and a larger number of observers could be pressed into service.

\section{Second deployment}

Date: 18 November 2010

Location: $27^{\circ} 54.9920^{\prime} \mathrm{S} 123^{\circ} 9.6561^{\prime} \mathrm{W}$

The second deployment of the large disc utilized a dozen observers, including one observer located almost directly above the disc, looking downward (Fig. F3). The disc was deployed $\sim 6 \mathrm{~h}$ after sunrise under partly cloudy conditions. The JOIDES Resolution, with its bow pointing east, allowed our observers on the fantail and helideck to have the sun behind them during the period of observation. Once again, however, moderately strong winds created suboptimal surface conditions. In an effort to maximize viewing conditions and reduce surface chop, the JOIDES Resolution master turned off the starboard rear propeller (Fig. F4). Although a lesser amount of chop resulted from this action, the continuing surface disturbances resulting from wind action continued to hinder our ability to decisively resolve the white and black pattern of the Secchi disc depth beyond 61.5 mbsl. To confirm this depth of observation, the disc was lowered an additional $2-3 \mathrm{~m}$ and then raised to $61.5 \mathrm{mbsl}$, where observers were able to positively identify the object.

\section{Preliminary results and recommendations for future deployments}

During Expedition 329, the JOIDES Resolution Secchi discs were deployed in the world's clearest marine water. The discs were deployed during the austral late spring, a time when chlorophyll abundance in the water is near its annual minimum value. The sun position (between 6 and $9 \mathrm{~h}$ following sunrise) and atmospheric conditions (clear to partly cloudy) of each deployment were nearly optimal. Deployment occurred on the JOIDES Resolution's fantail while the bow faced east, thus allowing us to minimize glare by keeping the sun slightly behind us. At the time of the observations, the JOIDES Resolution was dynamically positioned over the center of the gyre, a location as far from sources of wind-blown, water-clouding clay as possible. Therefore, we expected the depth of the SDT to be the greatest possible, in excess of the transparencies reported for the Sargasso Sea by Boguslawski and Krümmel (1907) and Visser (1967). 
Our results do not exceed those reported in the Sargasso Sea. The maximum confirmed depth of observation of our small $(40 \mathrm{~cm}$ diameter) disc was 46.5 mbsl, 2 m shallower than Visser's observation of 48.5 mbsl (acquired using a $30 \mathrm{~cm}$ diameter disc) but $5 \mathrm{~m}$ deeper than Krümmel's observation using a larger, 50 $\mathrm{cm}$ diameter disc. The maximum observed depth of our large disc was $5 \mathrm{~m}$ shallower than Visser's $(1 \mathrm{~m}$ diameter disc) and approximately in the middle of Krümmel's maximum observed depth range of 55.5$66.5 \mathrm{mbsl}$ that he acquired using a $2 \mathrm{~m}$ diameter disc.

Several options possibly explain these results:

1. The small amount of glare and chop we experienced was unique to our experiment. Our viewing conditions were somehow less ideal than those Krümmel and Visser experienced during their voyages.

2. The instrument is true and the method is sound; thus, the water of the central South Pacific Gyre is less transparent than water in the Sargasso Sea.

3. A Secchi disc is the quintessential scientific "blunt instrument" and is incapable of discerning the subtle differences that distinguish the world's clearest marine water from the world's second clearest marine water.

We believe option 3 is the most likely interpretation. Sufficient objective evidence exists to support the South Pacific Gyre's claim of being the world's most hyperoligotrophic water. We consider it unlikely that Visser, operating in the North Atlantic in February, enjoyed better observational conditions than we did. Thus, our conclusion is simple: the Secchi disc is not the right tool for investigating the clarity of water that allows light (PAR) to penetrate 100-150 mbsl.

The more important aspect of our work, we believe, is that the JOIDES Resolution's Secchi discs can now serve as showcases of water monitoring efforts and marine scientists' concern for the overall health of the world oceans. The best purpose of a Secchi disc is not to set records of greatest water transparency but rather to track changes in water quality that could be harbingers of lost water quality. For that purpose, the Secchi disc remains an important tool for scientists and citizens; therefore, we advocate the continued use of the JOIDES Resolution Secchi discs as a matter of routine shipboard operations and promotions during its journeys to all the world's oceans.

\section{Acknowledgments}

This work was supported by the Integrated Ocean Drilling Program (IODP). We would like to thank the crew of the R/V JOIDES Resolution for assistance with this study.

\section{References}

Boguslawski, G.H., and Krümmel, O., 1907. Handbuch der Ozeanographie: Stuttgart (J. Engelhorn).

Bukata, R.P., Jerome, J.H., and Bruton, J.E., 1988. Relationships among Secchi disk depth, beam attenuation coefficient, and irradiance attenuation coefficient for the Great Lakes waters. J. Great Lakes Res., 14(3):347-355 doi:10.1016/S0380-1330(88)71564-6

Cialdi, A., 1866. Relazione delle esperienze fatte a bordo della pontificia pirocorvetta Immacolata Concezione per determinare la transparenza del mare. Memoria del P. A. Secchi. In Cialdi, A., Sul Moto Ondoso del Mare e su le correnti di esso specialment su quelle littorali (2nd ed.): Rome (Tipografia delle Belle Arti), 258-288.

Clarke, G.L., 1939. Variation in the transparency of three areas of the Atlantic throughout the year. Ecology, 20(4):529-543. doi:10.2307/1930443

Claustre, H., Morel, A., Babin, M., Cailliau, C., Marie, D., Marty, J.-C., Tailliez, D., and Vaulot, D., 1999. Variability in particle attenuation and chlorophyll fluorescence in the tropical Pacific: scales, patterns, and biogeochemical implications. J. Geophys. Res., [Oceans], 104(C2):3401-3422. doi:10.1029/98JC01334

Claustre, H., Sciandra, A., and Vaulot, D., 2008. Introduction to the special section bio-optical and biogeochemical conditions in the South East Pacific in late 2004: the BIOSOPE program. Biogeosciences, 5(3):679-691. doi:10.5194/bg-5-679-2008

Expedition 329 Scientists, 2011. Site U1368. In D'Hondt, S., Inagaki, F., Alvarez Zarikian, C.A., and the Expedition 329 Scientists, Proc. IODP, 329: Tokyo (Integrated Ocean Drilling Program Management International, Inc.). doi:10.2204/iodp.proc.329.106.2011

Falkowski, P.G., and Wilson, C., 1992. Phytoplankton productivity in the North Pacific Ocean since 1900 and implications for absorption of anthropogenic $\mathrm{CO}_{2}$. Nature (London, U. K.), 358(6389):741-743. doi:10.1038/358741a0

Fougnie, B., Henry, P., Morel, A., Antoine, D., and Montagner, F., 2002. Identification and characterization of stable homogeneous oceanic zones: climatology and impact on in-flight calibration of space sensors over Rayleigh scattering. Ocean Optics XVI, 2002. http:// www.obs-vlfr.fr/LOV/OMT/fichiers_PDF/ Fougnie_et_al_OOXVI_02.pdf

Gordon, H.R., and McCluney, W.R., 1975. Estimation of the depth of sunlight penetration in the sea for remote sensing. Appl. Opt., 14(2):413-416. doi:10.1364/ AO.14.000413

Jerov, N.G., 1968. Optical Oceanography: New York (Elsevier).

Morel, A., Gentili, B., Claustre, H., Babin, M., Bricaud, A., Ras, J., and Tiéche, F., 2007. Optical properties of the 
"clearest" natural waters. Limnol. Oceanogr., 52(1):217229. http://www.aslo.org/lo/toc/vol_52/issue_1/ 0217.pdf

Morel, A., and Maritorena, S., 2001. Bio-optical properties of oceanic waters: a reappraisal. J. Geophys. Res., [Oceans], 106(C4):7163-7180. doi:10.1029/ 2000JC000319

Rea, D.K., Lyle, M.W., Liberty, L.M., Hovan, S.A., Bolyn, M.P., Gleason, J.D., Hendy, I.L., Latimer, J.C., Murphy, B.M., Owen, R.M., Paul, C.F., Rea, T.H.C., Stancin, A.M., and Thomas, D.J., 2006. Broad region of no sediment in the southwest Pacific Basin. Geology, 34(10):873-876. doi:10.1130/G22864.1
Riley, G.A., 1957. Phytoplankton of the north central Sargasso Sea, 1950-52. Limnol. Oceanogr., 2(3):252-270. http://www.jstor.org/stable/2832503

Tyler, J.E., 1968. The Secchi disc. Limnol. Oceanogr., 13(1):1-6. doi:10.4319/1o.1968.13.1.0001

Visser, M.P., 1967. Secchi disc and sea colour observations in the North Atlantic Ocean during the Navado III cruise, 1964-65, aboard H. Neth. M.S. "Snellius" (Royal Netherlands Navy). Neth. J. Sea Res., 3(4):553-563. doi:10.1016/0077-7579(67)90003-8

Publication: 13 December 2011 MS 329-111 
Figure F1. Photograph of the JOIDES Resolution Secchi discs. Photograph by Bryce Hoppie.

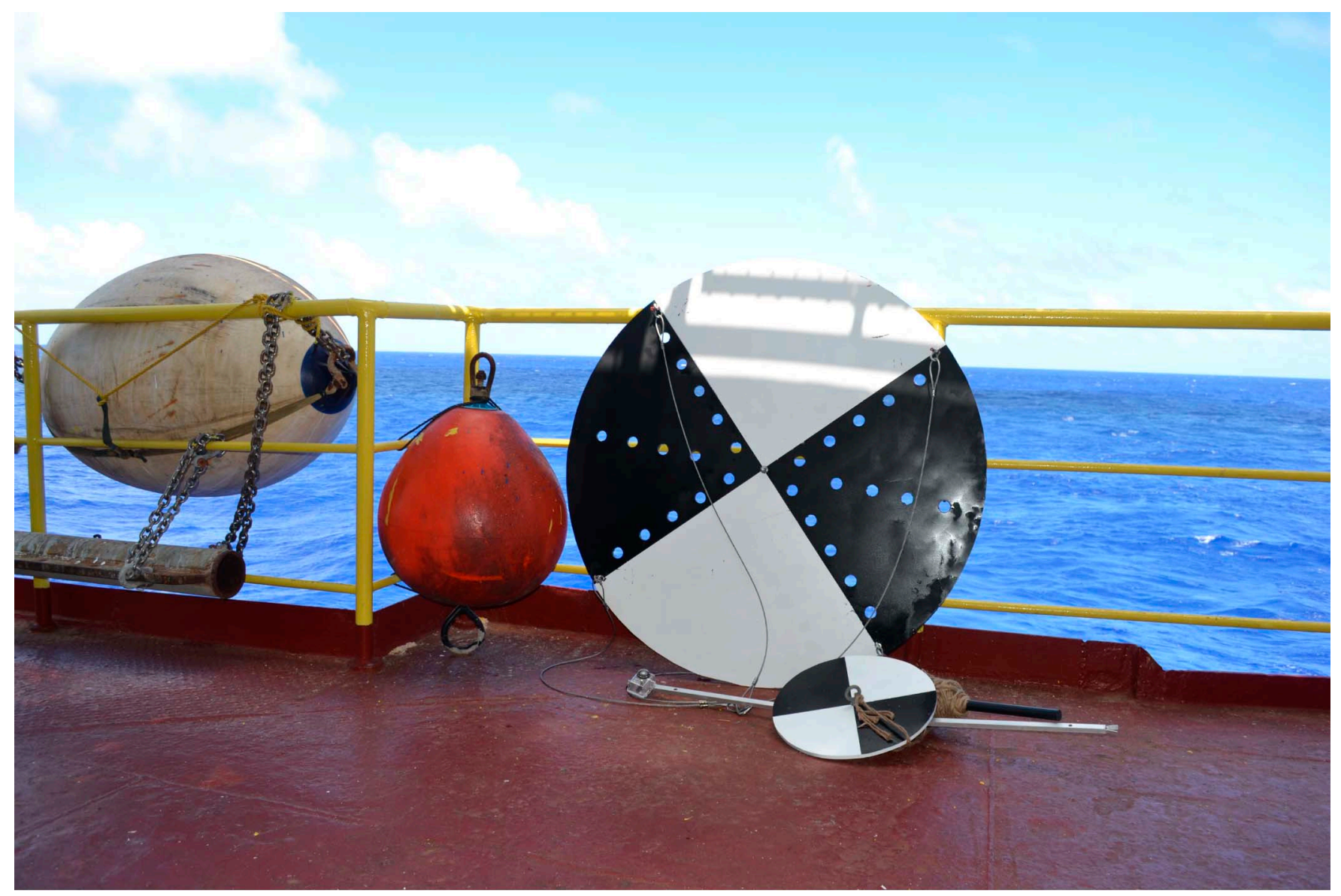


Figure F2. Photograph of JOIDES Resolution staff (Tim Bronk, Roy Davis, and Kristin Hillis) on the ship's helideck measuring the $46.7 \mathrm{~m}$ of rope used during the 13 November 2010 deployment of the small Secchi disc. Photograph by Bryce Hoppie.

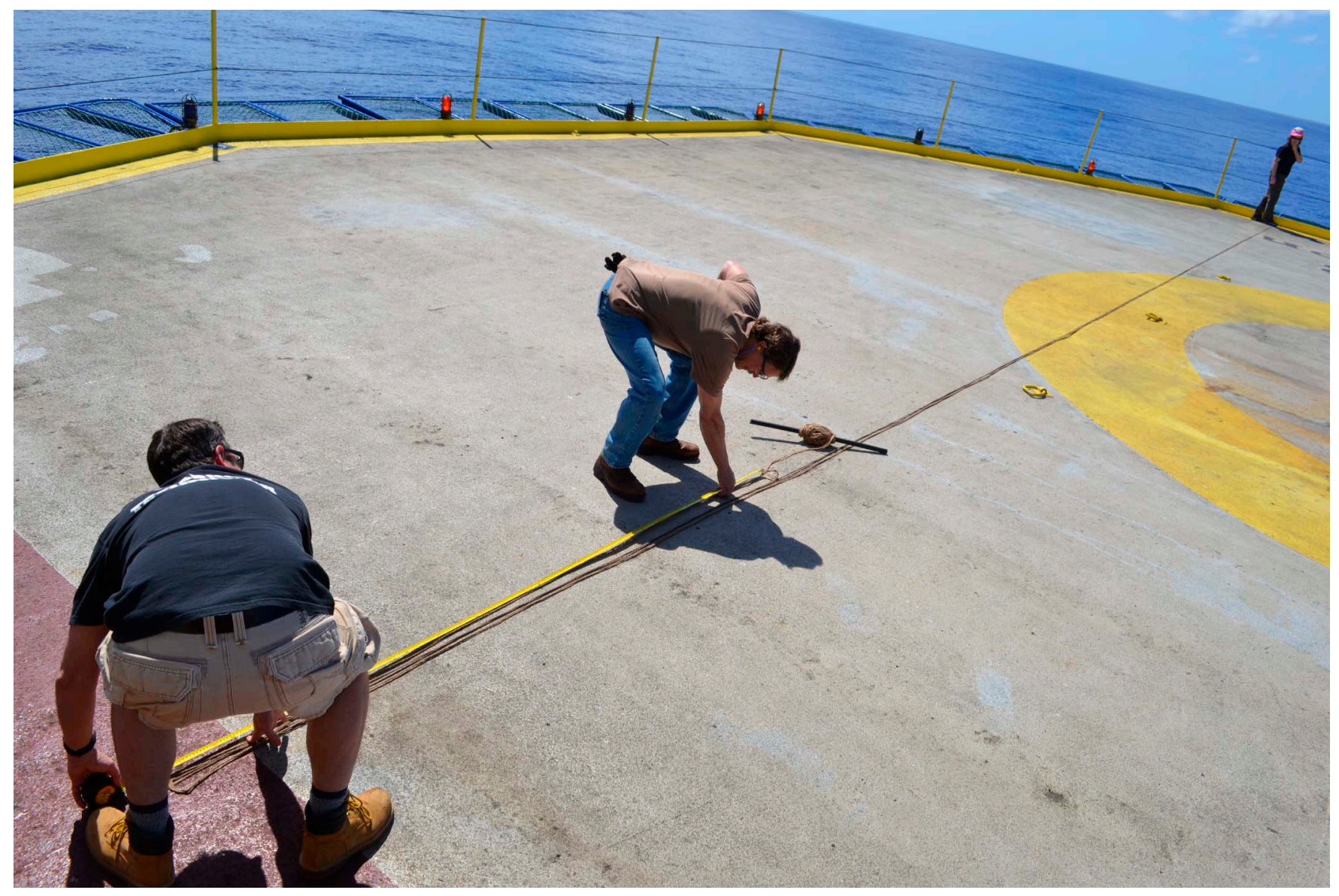


Figure F3. Photograph of 4 (of the 12) Secchi disc observers positioned directly above and at various other positions of the ship's fantail and helideck. Observers: Bryce Hoppie, Tim Bronk, Kristin Hillis, and Clayton Furman. Photograph by Fumio Inagaki.

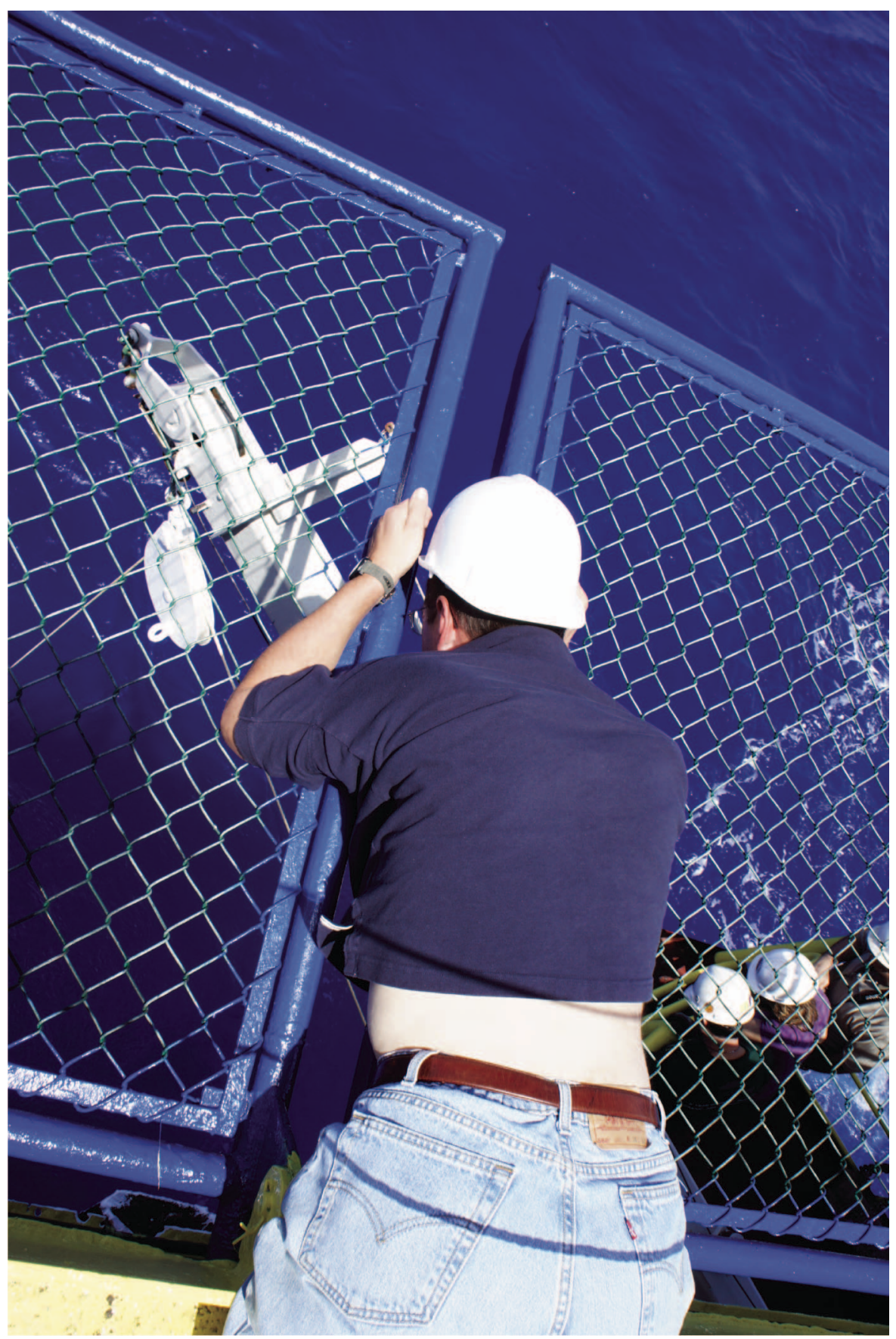


Figure F4. Photograph of the $1.2 \mathrm{~m}$ Secchi disc being retrieved following observations of water transparency off the JOIDES Resolution's fantail. Photograph by Fumio Inagaki.

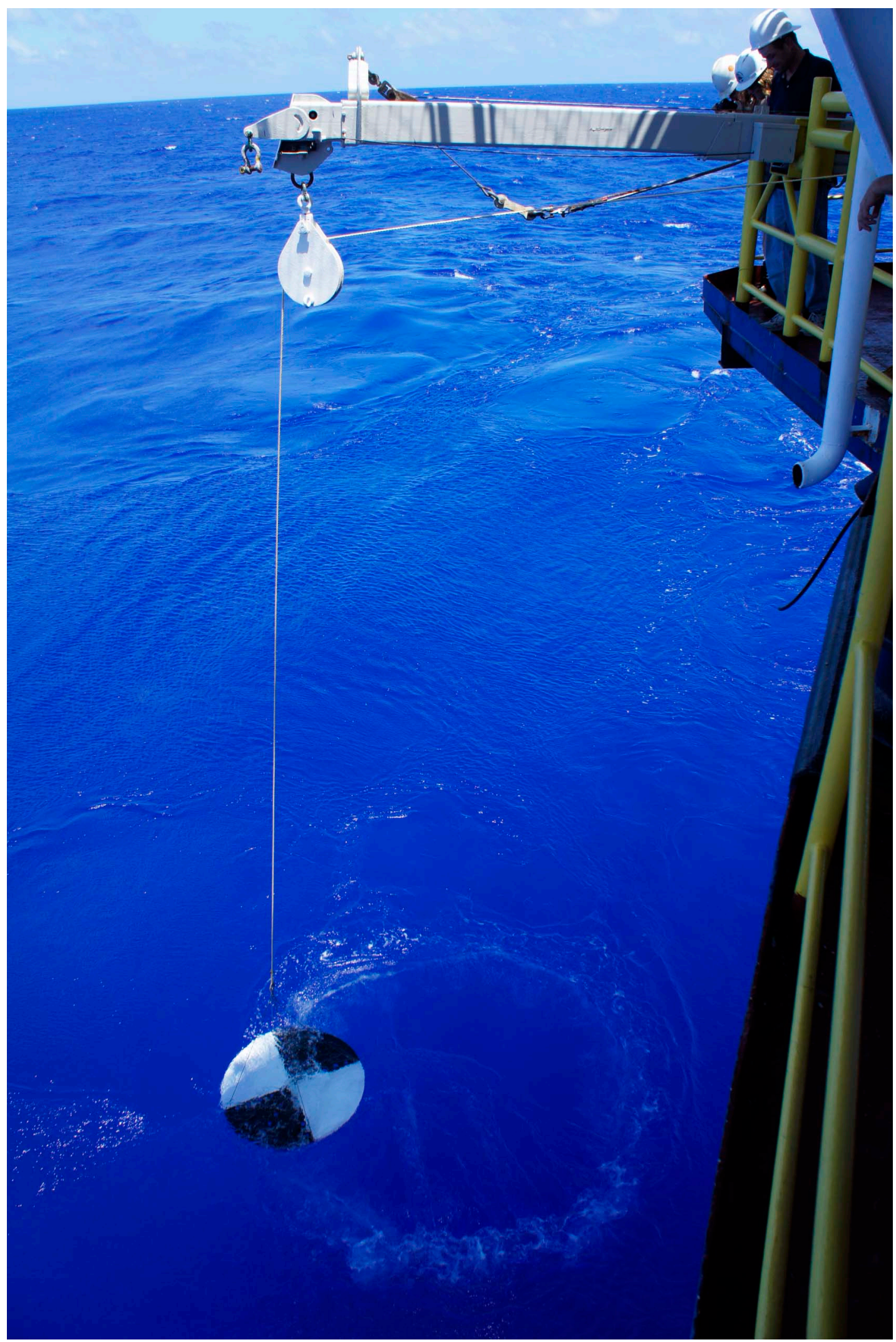

